\title{
SAMP1/Sku as a Murine Model for Tubulointerstitial Nephritis: a Study Using Unilateral Ureteral Obstruction
}

\author{
Akira YABUKI ${ }^{1)}$, Michie MAEDA' ${ }^{1)}$, Mitsuharu MATSUMOTO ${ }^{1)}$, \\ Ryozo KAMIMURA ${ }^{2)}$, Taku MASUYAMA ${ }^{3)}$, and Syusaku SUZUKI ${ }^{1)}$ \\ 1)Laboratory of Veterinary Anatomy, Faculty of Agriculture, Kagoshima University, 1-21-24 Korimoto, \\ Kagoshima 890-0065, 2)Division of Laboratory Animal Science, Research Center for Life Science \\ Resources, Kagoshima University, 8-35-1 Sakuragaoka, Kagoshima 890-8520, and \\ ${ }^{3}$ Toxicology Research Laboratories, Central Pharmaceutical Research Institute, \\ Japan Tobacco Inc., 23 Naganuki, Hadano 257-0024, Japan
}

\begin{abstract}
The SAMP1/Sku mouse is a substrain of the SAMP1 (senescence-acceleratedmouse prone 1) which exhibits renal mononuclear cell infiltration from a younger age. We hypothesized that this renal characteristic is related to the incidence of tubulointerstitial nephritis (TIN). The purpose of the present study was to evaluate the applicability of the SAMP1/Sku mouse as a murine model for TIN. TIN was experimentally induced by unilateral ureteral obstruction (UUO). The SAMP1/Sku and control ICR of both sexes received either a sham or UUO operation and were sacrificed 7 days after the operation. The kidneys of the mice were observed histopathologically, immunohistochemically and semiquantitatively. UUO kidneys showed mononuclear cell infiltration, tubular atrophy and interstitial fibrosis. In males, semiquantitative scores of mononuclear cell infiltration, tubular atrophy, and F4/80, $\alpha$-smooth muscle actin ( $\alpha$-SMA) and transforming growth factor (TGF)$\beta 1$ reactions were significantly higher in SAMP1/Sku than in ICR. Likewise, in females, tubular atrophy and F4/80 reaction scores were significantly higher in SAMP1/Sku than in ICR. In conclusion, induction of TIN damage by UUO was more serious in SAMP1/Sku mice than in ICR. Therefore, we propose that SAMP1/Sku mice, especially male SAMP1/ Sku, have congenital risk factors for the development of TIN.
\end{abstract}

Key words: immunohistochemistry, model animal, SAMP1/Sku, tubulointerstitial nephritis, unilateral ureteral obstruction

\section{Introduction}

It is now widely accepted that the rate of renal function deterioration strongly correlates with the degree of tubulointerstitial nephritis (TIN) $[2,8,30]$. TIN is one of the common histopathological features of progressive renal disease of diverse etiology $[9,12,20,27$, 31 , and its lesions consist of mononuclear cell infiltration, tubular atrophy and interstitial fibrosis [12]. Unilateral ureteral obstruction (UUO) is a well-estab-

(Received 16 September 2004 / Accepted 27 October 2004)

Address corresponding: A. Yabuki, Laboratory of Veterinary Anatomy, Faculty of Agriculture, Kagoshima University, 1-21-24 Korimoto, Kagoshima 890-0065, Japan 
lished experimental method for inducing progressive TIN [13, 15, 24], and UUO in rats and mice produces tubulointerstitial inflammation and fibrosis, which appears to mirror the human condition produced by obstructive uropathy $[10,17]$. The molecular and cellular mechanisms of TIN in the UUO kidney have been investigated and the involvement of various vasoactive agents, cytokines, chemokines and growth factors has been elucidated [14, 22].

The senescence-accelerated-mouse prone 1 (SAMP1) is a model of accelerated senility [25, 26]. The SAMP1/ Sku (previously called SAMP1//Ka) strain is a subline of the SAMP1, and we recently reported interesting biological and pathological characteristics of this strain [32]. Briefly, this mouse strain exhibits a long life span despite the misleading strain name, and their kidneys exhibit progressive mononuclear cell infiltration from a younger age (3-4 months old in the present study). Since mononuclear cell infiltration is a histopathological feature of TIN and is recognized as a key event for the development and progression of TIN [5, 10, 22, 23], we hypothesized that SAMP1/Sku congenitally possesses the risk factors for progressive TIN. However, no direct or related evidence has been reported to date.

In the present study, to evaluate the utility of SAMP1/ Sku as a murine model for TIN, the progression of TIN after UUO was histopathologically, immunochemically and semiquantitatively compared between the SAMP1/ Sku and an ordinal strain of mouse.

\section{Materials and Methods}

Animals: SAMP1/Sku and Jcl:ICR mice of both sexes were separated into the UUO group $(n=5$ for SAMP1/Sku of each sex, $n=4$ for ICR of each sex) and the sham-operation group ( $\mathrm{n}=3$ for each group). All mice were maintained in a one-way airflow system room (temperature $22 \pm 1{ }^{\circ} \mathrm{C}$; humidity $55 \pm 10 \%$; light period 07:00-19:00; ventilation 12 cycles/h) in the division of Laboratory Animal Science, Research Center for Life Science Resources, Kagoshima University. The present study was performed in accordance with the Guidelines for Animal Experimentation of Kagoshima University, Japan. The operation was performed under an anesthesia mixture of ketamine and medetomidine. UUO mice underwent left proximal ureter ligation. In the shamoperation, left ureters were exposed but not li- gated. To avoid infection, enrofloxacin $(5 \mathrm{mg} / \mathrm{kg})$ was administered intraperitoneally before the peritoneum was sutured. All mice underwent the UUO or sham operation at 3 months of age and were sacrificed by exsanguination of the carotid artery under anesthesia using a mixture of ketamine and medetomidine on day 7 after the operation. Kidneys were quickly removed.

Tissue preparation: Central slices from the kidneys, including the hilum, were cut perpendicular to the long axis and fixed in Zamboni's solution for 2 days at $4^{\circ} \mathrm{C}$. After routine embedding in paraffin, $3-\mu \mathrm{m}$-thick sections were cut every $30 \mu \mathrm{m}$ and stained with hematoxylin and eosin, periodic acid Schiff (PAS), periodic acid silvermethenamine or Masson's trichrome (MT) stains.

Immunohistochemistry was performed for detection of F4/80 as a macrophage marker, $\alpha$-smooth muscle actin (SMA) and transforming growth factor (TGF)- $\beta 1$. Deparaffinized sections were incubated with $3 \% \mathrm{H}_{2} \mathrm{O}_{2}$ to inhibit the endogenous peroxidase activity and then incubated with $1.5 \%(\mathrm{~V} / \mathrm{V})$ normal goat serum to reduce the non-specific reactions. For detection of $\alpha$-SMA, sections were incubated with mouse anti- $\alpha$-SMA monoclonal antibody (EPOS, peroxidase-conjugated; Dako Cytomation Co. Ltd., Glostrup, Denmark) for 60 $\min$ at room temperature $\left(20-25^{\circ} \mathrm{C}\right)$. For detection of $\mathrm{F} 4 / 80$, sections were incubated with biotinylated rat antimouse F4/80 (Caltag Laboratories, Burlingame, CA, USA) overnight at $4{ }^{\circ} \mathrm{C}$ and then incubated with peroxidase-conjugated avidin-biotin complex (ABC; VECTASTAIN Elite ABC Kit, Vector Laboratories, Inc., Burlingame, CA, USA) for $30 \mathrm{~min}$. For detection of TGF- $\beta 1$, sections were incubated with rabbit antiTGF- $\beta 1$ polyclonal antibody (Santa Cruz Biotechnology Inc, Santa Cruz, CA, USA) at $4^{\circ} \mathrm{C}$ overnight and then incubated with biotinylated goat anti-rabbit IgG polyclonal antibody (Vector Laboratories) for $30 \mathrm{~min}$ before the incubation with $\mathrm{ABC}$ solution. Immunoreactivity was detected with $0.025 \%$ (W/V) 3,3 '-diaminobenzidine- $0.003 \% \mathrm{H}_{2} \mathrm{O}_{2}$ solution. After stopping the reaction in distilled water, sections were counterstained with hematoxylin.

Semiquantitative morphometry: All sections were analyzed at random and the observer was blind with regard to the group. To objectively estimate the tubulointerstitial damage, the degree of mononuclear cell infiltration and tubular atrophy in the PAS sections, and interstitial fibrosis in the MT sections were 

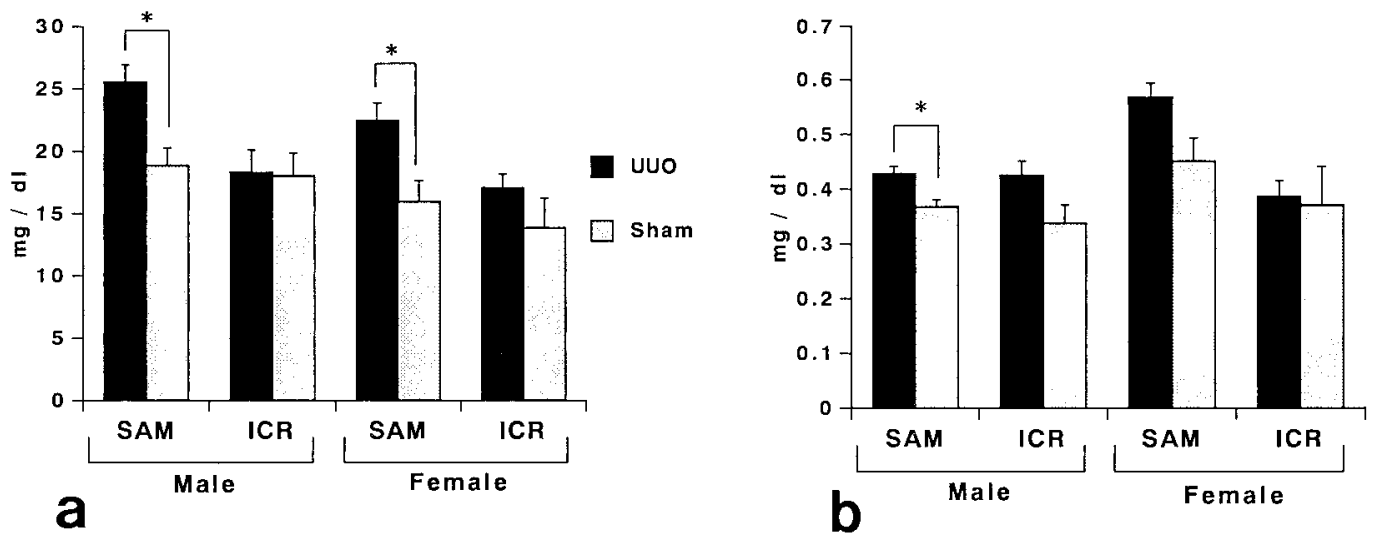

Fig. 1. Plasma blood urea nitrogen (BUN) and creatinine concentrations. (a) BUN. (b) Creatinine. UUO: unilateral ureter obstruction. Sham: sham operation. Each column represents the mean \pm S.E. *: significant differences $(P<0.05)$.

semiquantitatively analyzed. A grade from 0 (normal) to +4 (severe) was determined for at least 20 nonoverlapping fields (at $\times 200$ magnification) for each parameter, and the injury score for each parameter was calculated according to a previously reported formula [21]. Briefly, if three of the 20 fields displayed a lesion of +1 , five of 20 displayed a lesion of +2 , and two of 20 displayed a lesion of +3 , the final injury score would be: $\{(1 \times 3 / 20)+(2 \times 5 / 20)+(3 \times 2 / 20)\} \times 100$ $=95$. To estimate the expression of F4/80, $\alpha$-SMA and TGF- $\beta 1$, sections were observed at $\times 400$ magnification and expression scores were determined for each protein by the manner described above.

Blood biochemistry: Blood samples were collected in sampling tubes containing $1 \mathrm{mg}$ of ethylenediaminetetraacetic acid (EDTA-2Na) and 1,000 units of the kallikrein inhibitor aprotinin (Bayer Inc., Leverkusen, Germany). Plasma was obtained by centrifugation $\left(4,000\right.$ r.p.m for $10 \mathrm{~min}$ at $\left.4^{\circ} \mathrm{C}\right)$ and stored at $-20^{\circ} \mathrm{C}$ until use. Plasma concentrations of creatinine and blood urea nitrogen (BUN) were measured using a spectrophotometer (U-1500; Hitachi Inc., Tokyo, Japan) according to Jaffe's method using a creatinine test kit (Wako Pure Chemical Ltd., Osaka, Japan) and the urease-indophenol method using a nitrogen-B test kit (Wako Pure Chemical), respectively.

Statistical analysis: Results were regrouped and expressed as the mean \pm standard error (S.E.), and analyzed statistically using the Student's $t$-test. Statistical significance was defined as $P<0.05$.

\section{Results}

Blood biochemistry: In SAMP1/Sku mice of both sexes, plasma BUN concentrations were significantly higher in the UUO groups than in the sham operation groups (Fig. 1a). In male SAMP1/Sku, plasma creatinine concentrations were also higher in the UUO group than in the sham operation group, but no significant changes were detected in female SAMP1/Sku mice after UUO (Fig. 1b). In ICR mice of both sexes, no significant changes were detected in plasma BUN and creatinine concentrations after UUO.

Histopathology: The kidneys of SAMP1/Sku mice that underwent the sham operation (sham-kidneys) showed mild mononuclear cell infiltration around the interlobar or arcuate vessels. Although this mild infiltration was also observed in the kidneys contralateral to the ureteral obstruction (cont-kidneys), the degree of infiltration was similar to that of sham-kidneys. In ICR mice, no lesions were observed in the sham- and cont-kidneys.

Typical TIN lesions were observed in all kidneys that underwent ureteral obstruction (UUO-kidneys) (Fig. 2). Mononuclear cell infiltration was diffusely observed in the interstitium and was especially remarkable around the vessels. Uriniferous tubules from the proximal to collecting segments showed atrophic changes with a wrinkled thickening of the basement membrane, vacuolar or granular degeneration and urinary casts. Interstitial fibrosis was observed from the cortex to the medulla, and was especially severe in the medulla. 

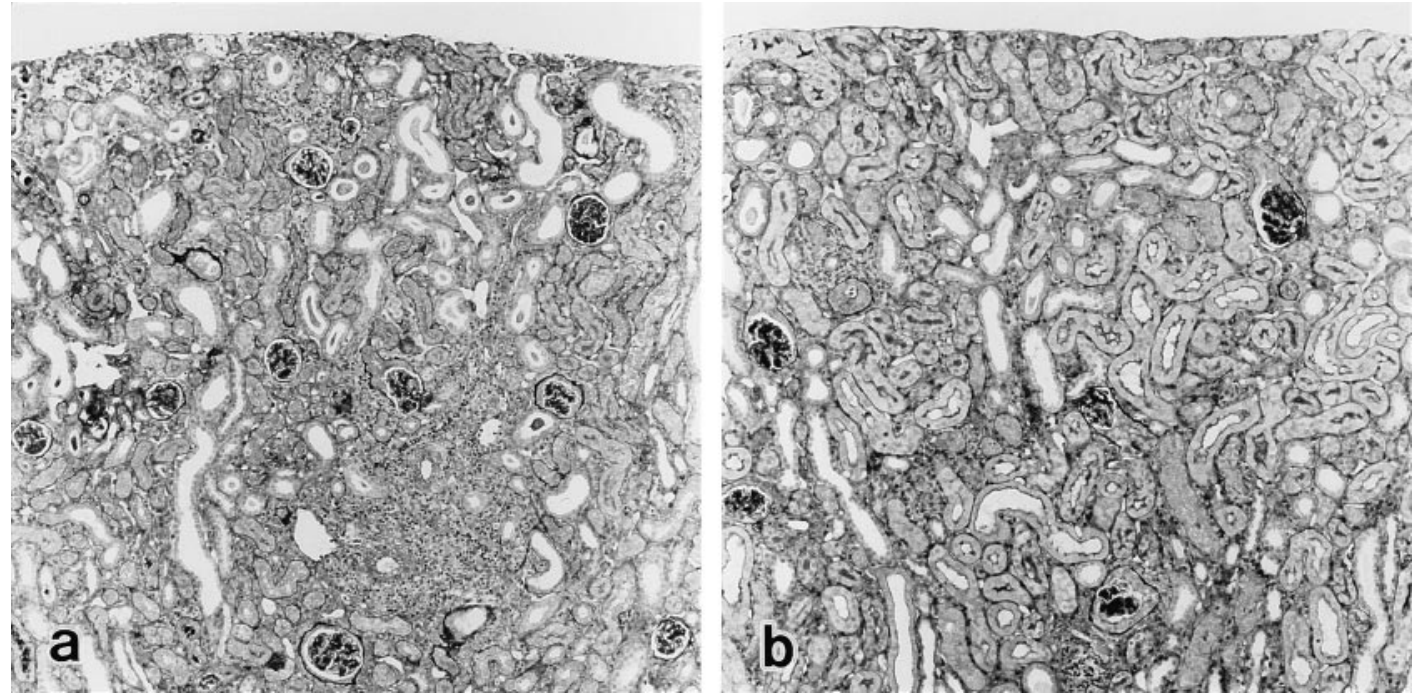

Fig. 2. Light micrographs of the UUO-kidney sections stained with PAS. (a) Male SAMP1/Sku. (b) Male ICR. Mononuclear cell infiltration and tubular atrophy are observed in the kidneys of SAMP1/Sku and ICR mice, and damage in SAMP1/Sku mice is more severe than in ICR mice. Magnification $\times 75$.
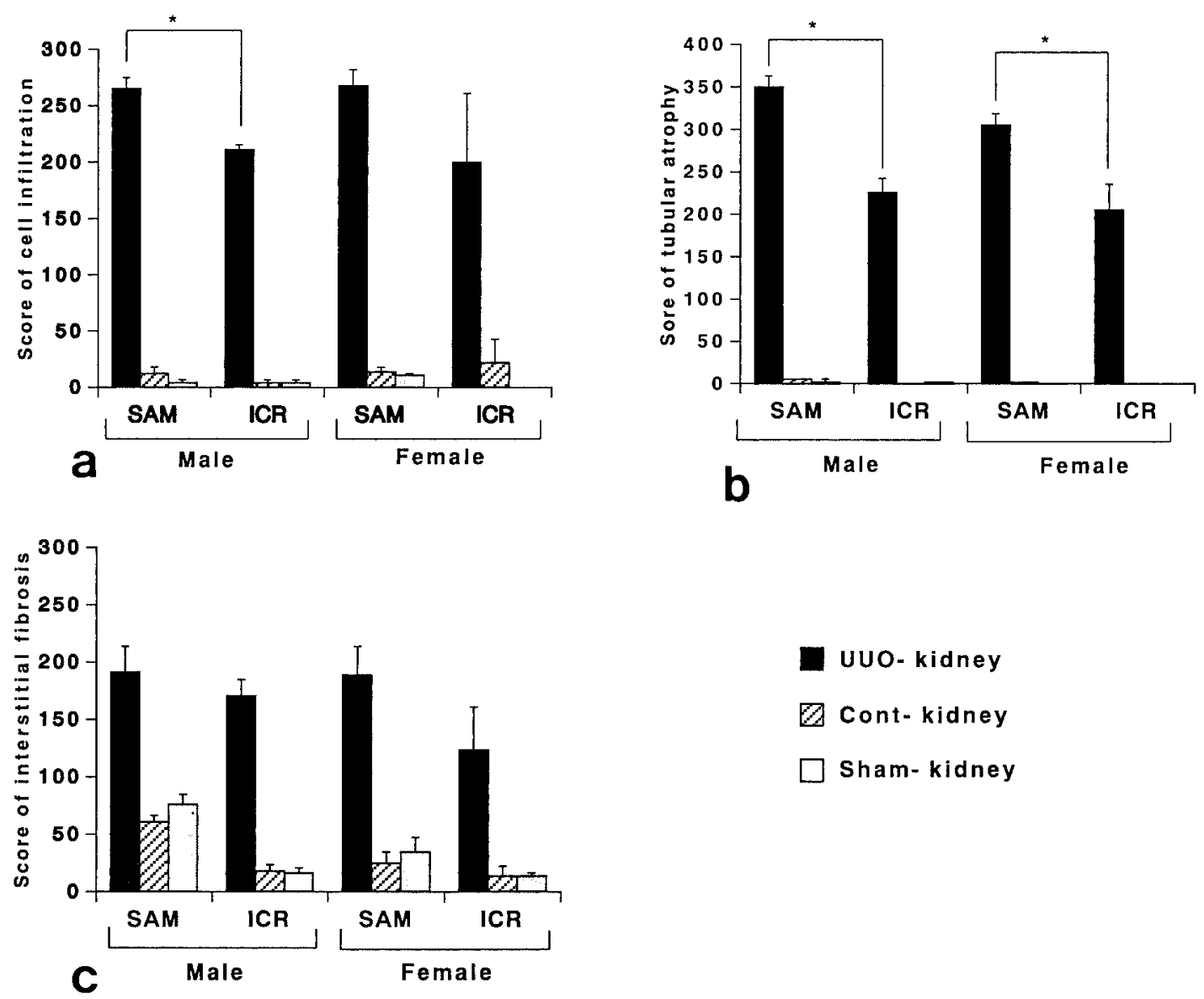

Fig. 3. Semiquantitative scores of tubulointerstital damage. (a) Mononuclear cell infiltration. (b) Tubular atrophy. (c) Interstitial fibrosis. Each column represents the mean \pm S.E. *: significant differences $(P<0.05)$. 

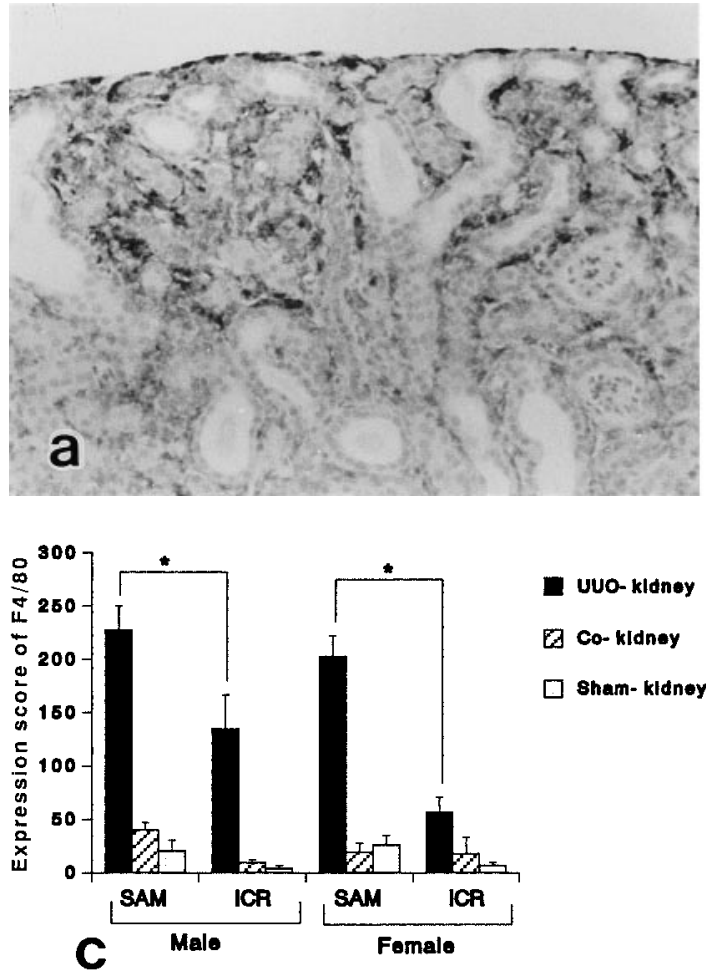

Figure 3 shows the injury scores of mononuclear cell infiltration, tubular atrophy and interstitial fibrosis. These three parameters exhibited elevated scores after UUO in male and female SAMP1/Sku and ICR mice. The cell infiltration score for UUO-kidneys in male SAMP1/Sku was significantly higher than that in male ICR (Fig. 3a). In females, no significant strain difference was detected in this parameter. The tubular atrophy score for SAMP1/Sku mice was significantly higher than that for ICR mice of either sex (Fig. 3b). No strain differences were detected for either sex in interstitial fibrosis (Fig. 3c).

Immunohistochemistry: $\mathrm{F} 4 / 80$ positive cells were rarely detected in the cortical interstitium of sham- and cont-kidneys of SAMP1/Sku and ICR mice. No positive reactions were detected in the few infiltrated cells found in the sham- and cont-kidneys of SAMP1/Sku. In UUO-kidneys, the number of F4/80 positive cells clearly increased in the cortical interstitium of both strains. The increase in positive cells after UUO was apparently greater in SAMP1/Sku than that in ICR mice (Figs. $4 \mathrm{a}$ and $\mathrm{b}$ ). These strain differences were confirmed semiquantitatively for each sex. F4/80

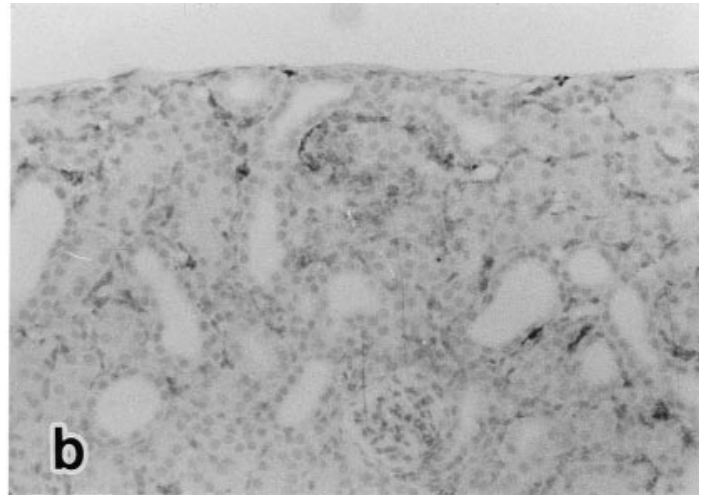

Fig. 4. Immunohistochemical detection and semiquantitative analysis of F4/80. (a) Light micrograph of a UUO-kidney section from male SAMP1/Sku. Immunoreactive cells for F4/80 are obviously observed in the cortical interstitium. (b) Light micrograph of a UUOkidney section from male ICR. Although immunoreactive cells for F4/80 are obviously observed in the cortical interstitium, they are apparently fewer in number than in SAMP1/ Sku. Magnification $\times 150$. (c) F4/80 expression scores. Each column represents the mean \pm S.E. * : significant differences $(P<0.05)$.

expression scores in UUO-kidneys were significantly higher in SAMP1/Sku than in ICR (Fig. 4c).

$\alpha$-SMA positive cells were commonly detected in blood vessel walls in sham- and cont-kidneys of both SAMP1/Sku and ICR mice. In UUO-kidneys, the number of $\alpha$-SMA positive cells clearly increased in the cortical and medullar interstitium, and this change was especially severe in male SAMP1/Sku (Figs. 5a and b). Semiquantitative analysis detected the highest $\alpha$-SMA expression score in the UUO-kidneys of male SAMP1/ Sku mice, and the score was significantly different from that of male ICR mice (Fig. 5c).

TGF- $\beta 1$ positive immunoreactions were rarely detected in sham- and cont-kidneys of SAMP1/Sku and ICR mice. In the UUO-kidneys, positive reactions were clearly detected in the apical portion of tubular epithelium, especially in the cortical tubules. Such positive reactions in the tubules were remarkable in the UUOkidneys of male SAMP1/Sku (Figs. 6a and b). Semiquantitative analysis detected the highest TGF- $\beta 1$ expression score in the UUO-kidneys of male SAMP1/ Sku, mice and the score was significantly higher than that in male ICR mice (Fig. 6c). 

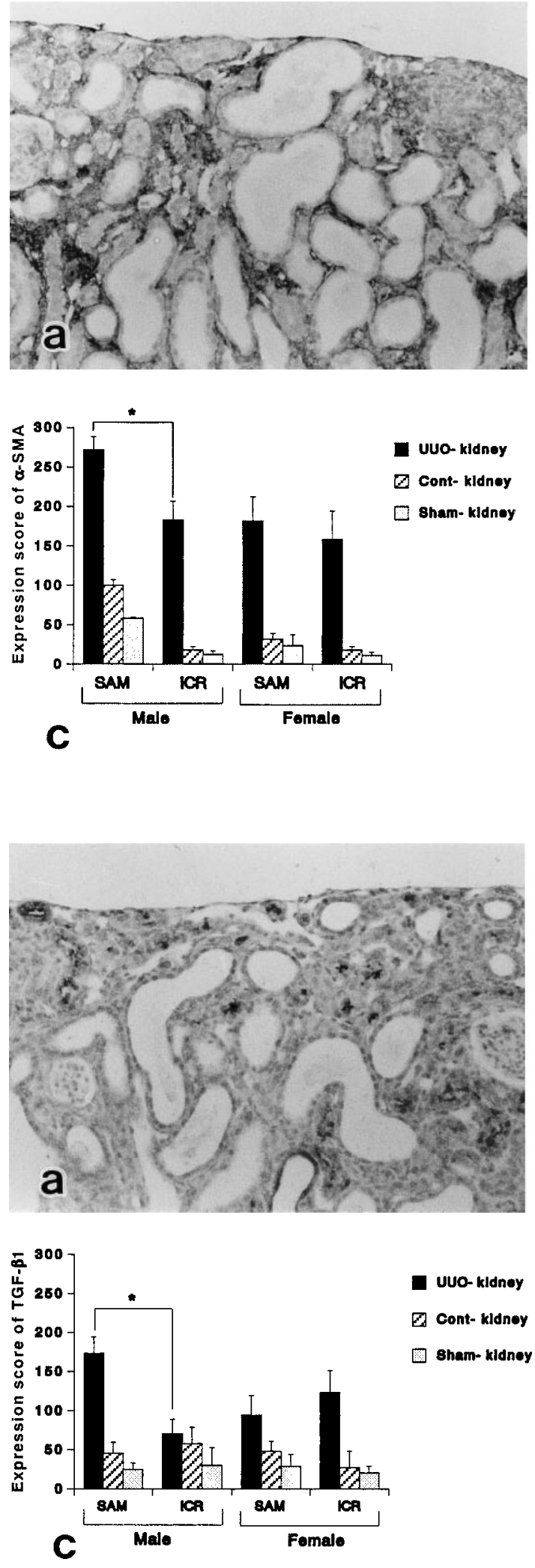

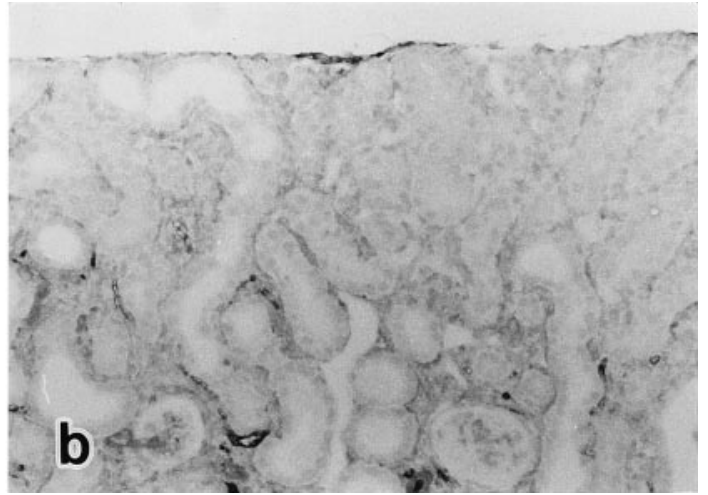

Fig. 5. Immunohistochemical detection and semiquantitative analysis of $\alpha$-smooth muscle actin (SMA). (a) Light micrograph a UUOkidney section from male SAMP1/Sku kidney. Severe immunoreactions for $\alpha$-SMA are observed in the interstitium. (b) Light micrograph a UUO-kidney section from male ICR kidney. Immunoreactions for $\alpha$-SMA are clearly milder than those in SAMP1/Sku. Magnification $\times 150$. (c) $\alpha$-SMA expression scores. Each column represents the mean \pm S.E. *: significant differences $(P<0.05)$.

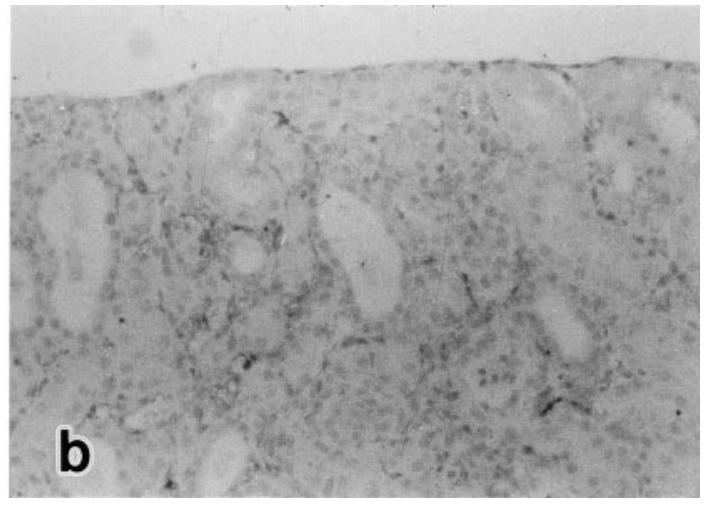

Fig. 6. Immunohistochemical detection and semiquantitative analysis of transforming growth factor (TGF)- $\beta 1$. (a) Light micrograph of a UUO-kidney section from male SAMP1/Sku. Immunoreactions for TGF- $\beta 1$ are observed in the apical portions of cortical tubules. (b) Light micrograph of a UUO-kidney section from male ICR. Immunoreactions for TGF- $\beta 1$ are clearly milder than those in SAMP1/Sku. Magnification $\times 150$. (c) TGF$\beta 1$ expression scores. Each column represents the mean \pm S.E. $*$ : significant differences $(P<0.05)$. 


\section{Discussion}

The SAMP1 was originally derived from the AKR/J strain of mouse [25, 26]. However, we used ICR mice as the healthy control in the present study, because spontaneous incidence of leukemia is well known in AKR mice [4].

No renal functional disorders could be diagnosed from plasma BUN and creatinine concentrations in UUO mice. We determined that these clinically normal conditions were caused by a compensatory increase in cont-kidney functions. However, a statistically significant increase in plasma BUN or creatinine concentration after UUO was found in SAMP1/Sku but not in ICR mice. Therefore, we suggest that functional deterioration of UUO-kidney in SAMP1/Sku mice is serious and cont-kidney function does not completely compensate for the damage.

Mononuclear cell infiltration is an important event in the pathogenesis of TIN [5, 10, 22, 23]. Infiltrated inflammatory cells cause tubular injury via production of cytokines such as interleukin-1 and tumor necrosis factor- $\alpha[22,28]$, then injured tubules cause more infiltration of macrophages and T-lymphocytes via production of chemokines such as monocyte chemoattractant peptide-1, osteopontin and intercellular adhesion molecules-1 [5, 29]. We recently reported that progressive mononuclear cell infiltration into the kidneys of SAMP1/Sku mice begins at 4 months old [32]. In the present study, we hypothesized that this model mouse congenitally possesses the risk factors of progressive TIN and severe TIN damage could be induced after UUO. The present findings demonstrate that infiltration of mononuclear cells, including F4/80positive macrophages, and tubular injury after UUO were more severe in SAMP1/Sku than in ICR. The findings in male SAMP1/Sku mice were as expected. Briefly, semiquantitative scores of mononuclear infiltration, tubular atrophy and F4/80 expression in UUO kidneys were significantly higher in male SAMP1/Sku than in male ICR mice.

Myofibroblasts are cells that share characteristics with fibroblasts and smooth muscle cells, and play an important role in wound contraction and healing [6]. However, myofibroblasts have also been implicated in the pathogenesis of tissue fibrosis and scarring [6]. Myofibroblasts play a major role in renal scarring and actively produce extracellular matrix molecules such as collagen types I, III and IV [6, 10]. Cytoskeletal proteins such as $\alpha$-SMA, desmin and vimentin are often expressed in myofibroblasts [18], and in particular, $\alpha$-SMA is considered a good marker for these cells [7]. The importance of tubular epithelial cells as the origin of myofibroblasts has been reported recently $[1,16]$. TGF- $\beta 1$ is a cytokine that plays a central role in tubular epithelial-myofibroblast transdifferentiation (TEMT). This cytokine is expressed in the damaged tubular cells or infiltrated macrophages and upregulates the TEMT via their receptor and intercellular Smad protein $[1,3,16]$. An increase in $\alpha$-SMA-positive myofibroblasts and overexpression of TGF- $\beta 1$ have been demonstrated previously in the UUO-kidney of experimentally induced UUO mice $[11,19]$. In the present study, UUO-kidneys of male SAMP1/Sku were expected to exhibit strong immunoreactivity for $\alpha$ SMA and TGF- $\beta 1$ because the most severe histopathological TIN damage under UUO was shown in male SAMP1/Sku. As a result, the increase in $\alpha$ SMA-positive myofibroblasts after UUO was especially prominent in male SAMP1/Sku mice. Immunoreaction for TGF- $\beta 1$ was clearly detected in the tubular epithelium in the UUO-kidneys, and its expression was also prominent in the male SAMP1/ Sku. Therefore, in UUO cases, rapid progression of TGF- $\beta 1$ mediated TEMT was demonstrated in the male SAMP1/Sku mice.

In conclusion, we performed UUO operations on SAMP1/Sku and control ICR mice, and seven days after the operation tubulointerstitial changes were compared histopathologically, immunohistochemically and semiquantitatively. Well-known pathological events of progressive TIN, involving infiltration of mononuclear cells including F4/80-positive macrophages, tubular atrophy and TGF- $\beta 1$ mediated TEMT, were induced in the SAMP1/Sku as well as in the ICR mice. However, the TIN damage in SAMP1/Sku was more severe than in ICR mice, especially in male SAMP1/ Sku. Therefore, our present findings suggest that SAMP1/Sku mice, especially male SAMP1/Sku, have congenital risk factors for the development and progression of TIN and are a murine model for clarifying the pathogenesis of this disease. 


\section{References}

1. Abbate, M., Zoja, C., Rottoli, D., Corna, D., Tomasoni, S., and Remuzzi, G. 2002. Proximal tubular cells promote fibrogenesis by TGF-beta1-mediated induction of peritubular myofibroblasts. Kidney Int. 61: 2066-2077.

2. Alexopoulos, E., Seron, D., Hartley, R.B., and Cameron, J. S. 1990. Lupus nephritis: correlation of interstitial cells with glomerular function. Kidney Int. 37: 100-109.

3. Böttinger, E.P. and Bitzer, M. 2002. TGF-beta signaling in renal disease. J. Am. Soc. Nephrol. 13: 2600-2610.

4. Coffin, J.M., Stoye, J.P., and Frankel, W.N. 1989. Genetics of endogenous murine leukemia viruses. Ann. N. Y. Acad. Sci. 567: 39-49.

5. Diamond, J.R., Ricardo, S.D., and Klahr, S. 1998. Mechanisms of interstitial fibrosis in obstructive nephropathy. Semin. Nephrol. 18: 594-602.

6. Gabbiani, G. 1992. The biology of the myofibroblast. Kidney Int. 41: 530-532.

7. Geleilete, T.J., Costa, R.S., Dantas, M., and Coimbra, T.M. 2001. Alpha-smooth muscle actin and proliferating cell nuclear antigen expression in focal segmental glomerulosclerosis: functional and structural parameters of renal disease progression. Braz. J. Med. Biol. Res. 34: 985-991.

8. Gilbert, R.E. and Cooper, M.E. 1999. The tubulointerstitium in progressive diabetic kidney disease: more than an aftermath of glomerular injury? Kidney Int. 56: 1627-1637.

9. Hannigan, N.R., Jabs, K., Perez-Atayde, A.R., and Rosen, S. 1996. Autoimmune interstitial nephritis and hepatitis in polyglandular autoimmune syndrome. Pediatr. Nephrol. 10: 511-514.

10. Hruska, K.A. 2002. Treatment of chronic tubulointerstitial disease: a new concept. Kidney Int. 61: 1911-1922.

11. Kawada, N., Moriyama, T., Ando, A., Fukunaga, M., Miyata, T., Kurokawa, K., Imai, E., and Hori, M. 1999. Increased oxidative stress in mouse kidneys with unilateral ureteral obstruction. Kidney Int. 56: 1004-1013.

12. Kelly, C.J. and Neilson, E.G. 1996. Tubulointerstitial diseases. pp. 1655-1679. In: The Kidney, 5th ed., (Brenner, B.M. eds), W. B Saunders, Philadelphia.

13. Klahr, S., Harris, K., and Purkerson, M.L. 1988. Effects of obstruction on renal functions. Pediatr. Nephrol. 2: 34-42.

14. Klahr, S. and Morrissey, J.J. 1998. The role of growth factors, cytokines, and vasoactive compounds in obstructive nephropathy. Semin. Nephrol. 18: 622-632.

15. Klahr, S. and Pukerson, M.L. 1994. The pathophysiology of obstructive nephropathy: the role of vasoactive compounds in the hemodynamic and structural abnormalities of the obstructed kidney. Am. J. Kidney Dis. 23: 219-223.

16. Lan, H.Y. 2003. Tubular epithelial-myofibroblast transdifferentiation mechanisms in proximal tubule cells. Curr. Opin. Nephrol. Hypertens. 12: 25-29.

17. Moller, J.C., Skriver, E., Olsen, S., and Maunsbach, A.B. 1984. Ultrastructural analysis of human proximal tubules and cortical interstitium in chronic renal disease (hydronephrosis). Virchows. Arch. A Pathol. Anat. Histopathol. 402: 209-237.
18. Muchaneta-Kubara, E.C. and El Nahas, A. M. 1997. Myofibroblast phenotypes expression in experimental renal scarring. Nephrol. Dial. Transplant. 12: 904-915.

19. Nagatoya, K., Moriyama, T., Kawada, N., Takeji, M., Oseto, S., Murozono, T., Ando, A., Imai, E., and Hori, M. 2002. Y-27632 prevents tubulointerstitial fibrosis in mouse kidneys with unilateral ureteral obstruction. Kidney Int. 61: 1684-1695.

20. Phillips, A.O. and Steadman, R. 2002. Diabetic nephropathy: the central role of renal proximal tubular cells in tubulointerstitial injury. Histol. Histopathol. 17: 247-252.

21. Raij, L., Azar, S., and Keane, W. 1984. Mesangial immune injury, hypertension, and progressive glomerular damage in Dahl rats. Kidney Int. 26: 137-143.

22. Razzaque, M.S. and Taguchi, T. 2002. Cellular and molecular events leading to renal tubulointerstitial fibrosis. Med. Electron. Microsc. 35: 68-80.

23. Schreiner, G.F., Harris, K.P., Purkerson, M.L., and Klahr, S. 1988. Immunological aspects of acute ureteral obstruction: immune cell infiltrate in the kidney. Kidney Int. 34: 487-493.

24. Sharma, A.K., Mauer, S.M., Kim, Y., and Michael, A.F. 1993. Interstitial fibrosis in obstructive nephropathy. Kidney Int. 44: 774-788.

25. Takeda, T., Hosokawa, M., and Higuchi, K. 1997. Senescence-accelerated mouse (SAM): a novel murine model of senescence. Exp. Gerontol. 32: 105-109.

26. Takeda, T., Matsushita, T., Kurozumi, M., Takemura, K., Higuchi, K., and Hosokawa, M. 1997. Pathobiology of the senescence-accelerated mouse (SAM). Exp. Gerontol. 32: 117-127.

27. Uchiyama-Tanaka, Y., Mori, Y., Kimura, T., Sonomura, K., Umemura, S., Kishimoto, N., Nose, A., Tokoro, T., Kijima, Y., Yamahara, H., Nagata, T., Masaki, H., Umeda, Y., Okazaki, K., and Iwasaka, T. 2004. Acute tubulointerstitial nephritis associated with autoimmunerelated pancreatitis. Am. J. Kidney Dis. 43: e18-25.

28. Vesey, D.A., Cheung, C.W., Cuttle, L., Endre, Z.A., Gobe, G., and Johnson, D.W. 2002. Interleukin-1beta induces human proximal tubule cell injury, alpha-smooth muscle actin expression and fibronectin production. Kidney Int. 62: $31-40$

29. Wang, Y., Rangan, G.K., Tay, Y.C., Wang, Y., and Harris, D.C. 1999 Induction of monocyte chemoattractant protein1 by albumin is mediated by nuclear factor kappaB in proximal tubule cells. J. Am. Soc. Nephrol. 10: 1204-1213.

30. Wehrmann, M., Bohle, A., Bogenschütz, O., Eissele, R., Freislederer, A., Öhlschlegel, C., Schumm, G., Batz, C., and Gartner, H.V. 1989. Long-term prognosis of chronic idiopathic membranous glomerulonephritis: an analysis of 334 cases with particular regard to tubulo-interstitial changes. Clin. Nephrol. 31: 67-76.

31. Wuthrich, R.P. and Sibalic, V. 1998. Autoimmune tubulointerstitial nephritis: insight from experimental models. Exp. Nephrol. 6: 288-293.

32. Yabuki, A., Suzuki, S., Matsumoto, M., and Nishinakagawa, H. 2002. Life span and renal morphological characterization of the SAMP1//Ka mouse. Exp. Anim. 51: 75-81. 